\title{
Editorial: Focused Collection: Quantitative Methods in PER: A Critical Examination
}

\author{
Alexis V. Knaub, ${ }^{1}$ John M. Aiken, ${ }^{1,2}$ and Marcos D. Caballero ${ }^{1,2}$ \\ ${ }^{1}$ Department of Physics and Astronomy, Michigan State University, East Lansing, Michigan 48823, USA \\ ${ }^{2}$ Center for Computing in Science Education \& Department of Physics, University of Oslo, \\ N-0316 Oslo, Norway
}

Published 3 July 2019

DOI: 10.1103/PhysRevPhysEducRes.15.020001

This Physical Review Physics Education Research (PRPER) Focused Collection was curated to provide a critical examination of the quantitative methods and practices used in Physics Education Research (PER). While quantitative research can be quite compelling as the work often includes large numbers of people and draws on the quantitative practices in which many physicists are trained, it also is full of decisions and nuances that can affect results and interpretation. These decisions and nuances, in turn, affect the utility of such data. Although we were interested in novel quantitative techniques or work (in general or with respect to PER), we also asked prospective authors to delve deeper and to question current practices in quantitative PER. Our aim was to ultimately draw out lessons that support the best possible quantitative research in PER. Such work exists in other disciplines and includes work where statistical conventions and practices are challenged [1-3]. This work also exists in PER, albeit not in mass quantities. Some areas explored include broad discussion of the facets of quantitative work in PER [4], issues surrounding concept inventory instruments [5-7], and choice in research design and definitions $[8,9]$.

The call for manuscripts was published on 15 June 2017 [10]. We received 43 proposals. In most cases, two guest editors and a Focused Collection advisory board member reviewed the proposals. We invited the authors of 26 proposals to submit a full manuscript.

We received 18 manuscripts by the extended deadline of 31 August 2018. The guest editors asked 2-3 reviewers to review each manuscript, which went through the standard PRPER review process. Twelve manuscripts were ultimately accepted for publication and can be grouped into three major areas.

One area includes papers that consider general concerns for quantitative PER. Ding created three genres of quantitative work in PER, noting the epistemological and ontological aspects of each genre along with practical implications to consider [11]. Knaub et al. conducted a two-phase study where quantitative experts familiar with PER identified fundamental issues regarding reporting of sample descriptions, conclusions, and limitations, and the authors examined PER manuscripts to learn the pervasiveness of these issues [12]. Springuel et al. examined how quantitative data are encoded, i.e., what information is kept and what is removed, and how such encoding impacts analysis [13]. Conlin et al. advocated the importance of publishing null results for PER [14].

The second area consists of manuscripts featuring methods that are not commonly used in PER work. Dou and Zwolak developed a guide for using social network analysis (SNA) and demonstrated what can be learned by applying SNA to student network data [15]. Nissen et al. presented multiple imputation as a means of rectifying missing data issues [16]. Zabriskie and Stewart used Conceptual Survey of Electricity and Magnetism (CSEM) data to demonstrate how Multidimensional Item Response Theory (MIRT) can be used [17]. Van Dusen and Nissen argued for and illustrated the use of hierarchical linear modeling to reveal important information in the data [18]. Stephens and Marder demonstrated that we might borrow ideas from fluid dynamics to avoid regression to the mean in longitudinal analyses [19].

The final major area consists of manuscripts that focused on comparing different techniques. Theobald et al. featured different types of regression that could be useful for PER and other discipline-based education research (DBER) [20]. Planinic et al. described the use of Rasch modeling, a type of analysis to better understand how respondents interact with various 
instruments or survey items, as well as dispelled myths associated with this technique [21]. Battaglia et al. used survey data to compare hierarchical and nonhierarchical cluster analysis and demonstrated the types of choices made with each method [22].

This Focused Collection offers the PER community with a variety of ideas to support and strengthen the work that we conduct. A number of authors pushed on our ideas of data and analysis providing an opportunity for an ongoing conversation about what researchers need to consider when designing, executing, and reporting a quantitative study [11-14]. Other authors highlighted analytical approaches that push the boundaries of quantitative PER or that solve persistent and common issues in our analyses [15-19]. Finally, some authors showed that using multiple analytical approaches to address the same problem will strengthen the work we do [20-22].

Our hope for this Focused Collection was to encourage researchers to publish more in-depth examinations of quantitative PER practices. Thus, we see this Focused Collection as a beginning to a larger conversation on how PER conducts and uses quantitative work. As the collection indicates, quantitative methods and practices are not static. Continuing this critical conversation about the work we do is important.

We thank Charles Henderson and the PRPER editorial board for their feedback. Debbie Brodbar, Managing Editor, provided incredible support and advice throughout the entire process. Our advisory board members for this Focused Collection (Lin Ding, Paula Engelhardt, Xiufeng Liu, Tim Stelzer, and John Stewart) contributed valuable insights. We thank the authors for submitting proposals and manuscripts, as this Focused Collection would not exist without them. Lastly, we thank the reviewers whose service is much appreciated.

[1] D. McNeish, Challenging conventional wisdom for multivariate statistical models with small samples, Rev. Educ. Res. 87, 1117 (2017).

[2] R. K. Henson and J. K. Roberts, Use of exploratory factor analysis in published research: Common errors and some comment on improved practice, Educ. Psychol. Meas. 66, 393 (2006).

[3] R. L. Wasserstein and N. A. Lazar, The ASA's statement on pvalues: Context, process, and purpose, The American Statistician 70, 129 (2016).

[4] L. Ding and X. Liu, Getting started with quantitative methods in physics education research, in Getting Started in PER, Reviews in PER Vol. 2, edited by C. Henderson and K. A. Harper (American Association of Physics Teachers, College Park, MD, 2012).

[5] M. Wittmann, Limitations in predicting student performance on standardized tests, presented at the Physics Education Research Conference 2002, Boise, Idaho (2002), https:// www.compadre.org/per/items/detail.cfm?ID=4311.

[6] P. Eaton, K. Johnson, B. Frank, and S. Willoughby, Classical test theory and item response theory comparison of the brief electricity and magnetism assessment and the conceptual survey of electricity and magnetism. Phys. Rev. Phys. Educ. Res. 15, 010102 (2019).

[7] R. Lindell, E. Peak, and T. Foster, Are they all created equal? A comparison of different concept inventory development methodologies, presented at the Physics Education Research Conference 2006, Syracuse, New York (2006), https://www.compadre.org/per/items/detail.cfm?ID=5267.
[8] D. Meltzer, The questions we ask and why: Methodological orientation in physics education research, presented at the Physics Education Research Conference 2003, Madison, Wisconsin (2003), https://www.per-central.org/items/ detail.cfm?ID=2717.

[9] I. Rodriguez, E. Brewe, V. Sawtelle, and L. H. Kramer, Impact of equity models and statistical measures on interpretations of educational reform, Phys. Rev. ST Phys. Educ. Res. 8, 020103 (2012).

[10] C. Henderson, Editorial: Call for Papers for Focused Collection: Quantitative Methods in PER: A Critical Examination, Phys. Rev. Phys. Educ. Res. 13, 010002 (2017).

[11] L. Ding, Theoretical perspectives of quantitative physics education research, Phys. Rev. Phys. Educ. Res. 15, 020101 (2019).

[12] A. V. Knaub, J. M. Aiken, and L. Ding, Two-phase study examining perspectives and use of quantitative methods in physics education research, Phys. Rev. Phys. Educ. Res. 15, 020102 (2019).

[13] R. P. Springuel, M. C. Wittmann, and J. R. Thompson, Reconsidering the encoding of data in physics education research, Phys. Rev. Phys. Educ. Res. 15, 020103 (2019).

[14] L. D. Conlin, E. Kuo, and N. R. Hallinen, How null results can be significant for physics education research, Phys. Rev. Phys. Educ. Res. 15, 020104 (2019).

[15] R. Dou and J. P. Zwolak, Practitioner's guide to social network analysis: Examining physics anxiety in an activelearning setting, Phys. Rev. Phys. Educ. Res. 15, 020105 (2019). 
[16] J. Nissen, R. Donatello, and B. Van Dusen, Missing data and bias in physics education research: A case for using multiple imputation, Phys. Rev. Phys. Educ. Res. 15, 020106 (2019).

[17] C. Zabriskie and J. Stewart, Multidimensional Item Response Theory and the Conceptual Survey in Electricity and Magnetism, Phys. Rev. Phys. Educ. Res. 15, 020107 (2019).

[18] B. Van Dusen and J. Nissen, Modernizing use of regression models in physics education research: A review of hierarchical linear modeling, Phys. Rev. Phys. Educ. Res. 15, 020108 (2019).

[19] S. Stephens and M. Marder, Longitudinal predictions using regression-corrected grouping to reduce regression to the mean, Phys. Rev. Phys. Educ. Res. 15, 020109 (2019).

[20] E. J. Theobald, M. Aikens, S. Eddy, and H. Jordt, Beyond linear regression: A reference for analyzing common data types in discipline based education research, Phys. Rev. Phys. Educ. Res. 15, 020110 (2019).

[21] M. Planinic, W. J. Boone, A. Susac, and L. Ivanjek, Rasch analysis in physics education research: Why measurement matters, Phys. Rev. Phys. Educ. Res. 15, 020111 (2019).

[22] O. R. Battaglia, B. Di Paola, and C. Fazio, Unsupervised quantitative methods to analyze student reasoning lines: Theoretical aspects and examples, Phys. Rev. Phys. Educ. Res. 15, 020112 (2019). 